ARTICLE

https://doi.org/10.1038/s41467-019-13755-5

\title{
Ultrastable Au nanoparticles on titania through an encapsulation strategy under oxidative atmosphere
}

\author{
Shaofeng Liu ${ }^{1,2,3}$, Wei $\mathrm{Xu}^{4,5}$, Yiming Niu${ }^{6}$, Bingsen Zhang ${ }^{6}{ }^{6}$, Lirong Zheng ${ }^{4}$, Wei Liu ${ }^{1}$, Lin $\mathrm{Li}^{1} \&$ \\ Junhu Wang (1) ${ }^{1,2 \star}$
}

Supported gold catalysts play a crucial role in the chemical industry; however, their poor onstream stability because of the sintering of the gold nanoparticles restricts their practical application. The strong metal-support interaction (SMSI), an important concept in heterogeneous catalysis, may be applied to construct the structure of catalysts and, hence, improve their reactivity and stability. Here we report an ultrastable Au nanocatalyst after calcination at $800^{\circ} \mathrm{C}$, in which $\mathrm{Au}$ nanoparticles are encapsulated by a permeable $\mathrm{TiO}_{x}$ thin layer induced by melamine under oxidative atmosphere. Owning to the formed $\mathrm{TiO}_{x}$ overlayer, the resulting Au catalyst is resistant to sintering and exhibits excellent activity and stability for catalytic $\mathrm{CO}$ oxidation. Furthermore, this special strategy can be extended to colloidal Au nanoparticles supported on $\mathrm{TiO}_{2}$ and commercial gold catalyst denoted as $\mathrm{RR} 2 \mathrm{Ti}$, providing a universal way to engineer and develop highly stable supported Au catalysts with tunable activity.

\footnotetext{
${ }^{1}$ State Key Laboratory of Catalysis, Dalian Institute of Chemical Physics, Chinese Academy of Sciences, Dalian 116023, China. ${ }^{2}$ Mössbauer Effect Data Center, Dalian Institute of Chemical Physics, Chinese Academy of Sciences, Dalian 116023, China. ${ }^{3}$ University of Chinese Academy of Sciences, Beijing 100049, China. ${ }^{4}$ Institute of High Energy Physics, Chinese Academy of Sciences, Beijing 100049, China. ${ }^{5}$ Rome International Center for Materials Science Superstripes, Via dei Sabelli 119A, 00185 Rome, Italy. ${ }^{6}$ Shenyang National Laboratory of Materials Science, Institute of Metal Research, Chinese Academy of Sciences, Shenyang 110016, China. *email: wangjh@dicp.ac.cn
} 
S upported catalysts, dispersed on high specific area, are one of the most important heterogeneous catalysts ${ }^{1,2}$. The primary role of the support is ascribed to increase the dispersion of metal and stabilize the active sites. And the interaction between metal and support named carried effects are also recognized to play a vital role in tuning the activity, selectivity and stability of the catalysts ${ }^{2-8}$. However, much less is known about how meal-support interaction will affect the activity and selectivity of metal-oxide supported catalysts ${ }^{9,10}$.

Gold catalysts have been developed for several industrial processes because of their unique catalytic activity ${ }^{11-17}$. However, poor on-stream stability resulting from $\mathrm{Au}$ nanoparticles (NPs) sintering restricts their practical application ${ }^{18,19}$. Up to now, some strategies have been proposed to increase the stability of $\mathrm{Au}$ NPs in high-temperature reactions, including fixing the Au NPs inside porous channels, coating the Au NPs with thin shells of carbon or porous oxide and strengthening the meal-support interaction. However, there are still some issues remain to be resolved although great progresses have been achieved ${ }^{20-35}$. For example, Au NPs inside the porous channels are tending to sinter because the pores are poorly controlled ${ }^{20,21}$. As for coating strategy, which may cover the active sites and/or lead diffusion limitations, therefore will reduce the activity although it can stabilize the Au NPs in a degree 22,36 . Comparatively, encapsulating Au NPs with reducible oxide overlayer is valid, achieved by constructing an oxide barrier on the surface of Au NPs, which is known as strong metal-support interaction (SMSI) ${ }^{27-30}$. Generally, strong metal-support interaction (SMSI; now denoted as classical SMSI) was first described by Tauster et al. in the late 1970 s to explain the dramatically suppressed $\mathrm{CO}$ and $\mathrm{H}_{2}$ adsorption on titania-supported platinum group metals after high-temperature reduction treatment ${ }^{37}$. From then on, SMSI has been investigated comprehensively and an agreement has been reached that SMSI emanates from the encapsulation of metals by supports $^{38,39}$. Up to now, SMSI has been exploited to enhance catalytic performance of the catalysts by modifying the electronic and geometric factors of the metal NPs ${ }^{27,40-48}$.

For long ages it has been well-recognized that $\mathrm{Au}$ cannot manifest SMSI, which was ascribed to its low work function and surface energy and its low ability to dissociate $\mathrm{H}_{2}$ to active the support in the previous investigation ${ }^{49-52}$. Under this assumption, a few successes have been achieved that an oxide overlayer can be formed on gold supported on $\mathrm{ZnO}$, hydroxyapatite and phosphate supports in oxygen atmosphere, contrary to the condition required for classical SMSI ${ }^{27,53,54}$. Later, we demonstrated the existence of classical SMSI between $\mathrm{Au}$ and $\mathrm{TiO}_{2}$ and the encapsulation of $\mathrm{Au}$ by $\mathrm{TiO}_{x}$ overlayer was also observed ${ }^{28}$. Recently, Xiao et al. constructed a $\mathrm{TiO}_{x}$ overlayer on $\mathrm{Au}$ NPs via wet-chemical strategy in a relative mild condition without reduction pretreatment ${ }^{30}$. More excitingly, Christopher et al. proposed that the adsorbates $\mathrm{HCO}_{x}$ on $\mathrm{TiO}_{2^{-}}$and $\mathrm{Nb}_{2} \mathrm{O}_{5}$-supported $\mathrm{Rh}$ catalysts could induce the encapsulation of Rh NPs by supports in $\mathrm{CO}_{2}-\mathrm{H}_{2}$ environment at temperatures of $150-300{ }^{\circ} \mathrm{C}$, denoted as adsorbate-mediated SMSI (A-SASI) ${ }^{46}$.

Herein, we demonstrate that Au NPs can be encapsulated by a permeable $\mathrm{TiO}_{\mathrm{x}}$ overlayer under oxidative atmosphere induced by melamine, the reverse of condition required for classical SMSI between $\mathrm{Au}$ and $\mathrm{TiO}_{2}^{28}$. The key to construct the overlayer is the application of melamine and pretreatment in nitrogen gas, followed by calcination at $800^{\circ} \mathrm{C}$ in air atmosphere, which strengthen the interaction between $\mathrm{Au}$ and $\mathrm{TiO}_{2}$. Owning to the formation of the overlayer, the resultant catalyst is sinteringresistant with high activity after calcination at $800^{\circ} \mathrm{C}$ as well as excellent durability in a simulated practical testing, implying the potential for practical application. More importantly, this special strategy can be extended to colloidal Au NPs supported on $\mathrm{TiO}_{2}$ and commercial gold catalyst denoted as RR2Ti, which enables to rationally devise and develop highly stable supported Au catalysts with controllable activity.

\section{Results}

Physical and chemical nature of the encapsulation layer. The catalysts were prepared with deposition-precipitation (DP) method and followed by modification with melamine and pretreatment at $600{ }^{\circ} \mathrm{C}$ in $\mathrm{N}_{2}$ atmosphere and further calcination at $800^{\circ} \mathrm{C}$ in air. High-resolution transmission electron microscopy (HRTEM) (Fig. 1) showed the morphology change of Au NPs during synthesis. For the as-prepared $\mathrm{Au} / \mathrm{TiO}_{2}$, the average particle size of gold was about $3.5 \mathrm{~nm}$ after pretreatment at $250{ }^{\circ} \mathrm{C}$ in air (Fig. 1a and Supplementary Fig. 1a). After modification with melamine (denoted as $\mathrm{Au} / \mathrm{TiO}_{2} @ \mathrm{M}$ ), the particle size increased to $3.6 \mathrm{~nm}$. However, no melamine was observed on the surface of $\mathrm{Au}$ NPs, which was different from the previous work (Fig. $1 \mathrm{~b}$ and Supplementary Fig. 1b) $)^{23}$. When calcination at $600^{\circ} \mathrm{C}$ in $\mathrm{N}_{2}$ atmosphere for $3 \mathrm{~h}$ (denoted as $\mathrm{Au} / \mathrm{TiO}_{2} @ \mathrm{M}-\mathrm{N}$ ), the change in the interface was observed, suggesting the variation of the interaction between $\mathrm{Au}$ NPs and support (Fig. 1c). Meanwhile, the $\mathrm{Au}$ NPs size increased from 3.6 to $6.7 \mathrm{~nm}$ (Supplementary Fig. 1c). Surprisingly, after being subjected to calcination at $800^{\circ} \mathrm{C}$ in air (denoted as $\mathrm{Au} / \mathrm{TiO}_{2} @ \mathrm{M}-\mathrm{N}-800$ ) it was found that Au NPs were covered with an overlayer, which should be from $\mathrm{TiO}_{2}$ as melamine would decomposed completely in this condition (Fig. 1d and Supplementary Fig. 2). Meanwhile, the Au NPs size was only about $7.5 \mathrm{~nm}$, indicating a robust sintering-resistant $\mathrm{Au}$ nanocatalyst (Supplementary Fig. 1d). It is worth noting that the smaller $\mathrm{Au}$ NPs can also be encapsulated similarly to that of the larger ones (Supplementary Fig. 3). However, it is difficult to observe the morphology and encapsulation of gold when the Au NPs size is less than $2 \mathrm{~nm}$. And it was calculated that more than $90 \%$ of $\mathrm{Au}$ NPs was encapsulated based on the particle size distribution. Comparatively, for the $\mathrm{Au} / \mathrm{TiO}_{2}$ catalyst without melamine modification after pretreatment at $800{ }^{\circ} \mathrm{C}$ (denoted as $\mathrm{Au} / \mathrm{TiO}_{2}$ 800), the catalyst sintered seriously with a particle size about 32.6 $\mathrm{nm}$ and no cover layer was observed (Supplementary Fig. 4).

The above results were further examined by X-ray diffraction (XRD) patterns. As pictured in Supplementary Fig. 5, there was no diffraction peaks ascribed to $\mathrm{Au}$ NPs for $\mathrm{Au} / \mathrm{TiO}_{2}$ and $\mathrm{Au} /$ $\mathrm{TiO}_{2} @ \mathrm{M}$, suggesting that Au NPs were dispersed uniformly, in agreement with TEM results. While after calcination, diffraction peaks of $\mathrm{Au}(111)$ at $38.2^{\circ}$ and $\mathrm{Au}(200)$ at $44^{\circ}$ were observed for

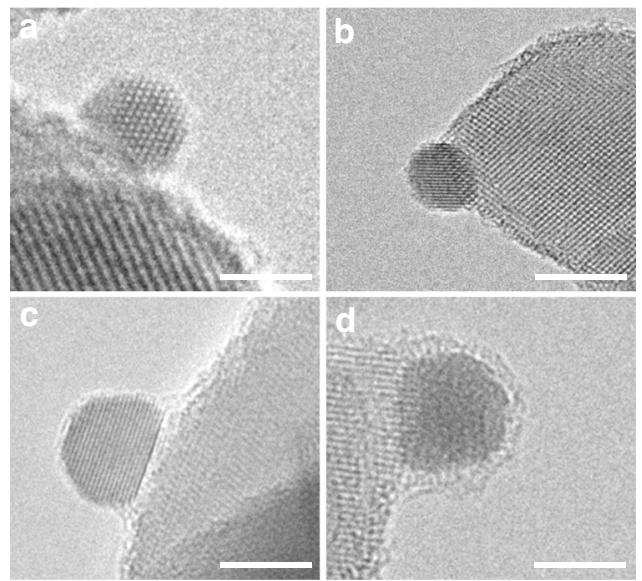

Fig. 1 HRTEM analysis. a HRTEM image of $\mathrm{Au} / \mathrm{TiO}_{2}$. b HRTEM image of $\mathrm{Au} / \mathrm{TiO}_{2} @ \mathrm{M}$. c HRTEM image of Au/TiO ${ }_{2} @ \mathrm{M}-\mathrm{N}$. $\mathbf{d}$ HRTEM image of Au/ $\mathrm{TiO}_{2} @ \mathrm{M}-\mathrm{N}-800$. The scale bar corresponds to $5 \mathrm{~nm}$. Additional results for these samples can be found in Supplementary Figs. 1-3. 

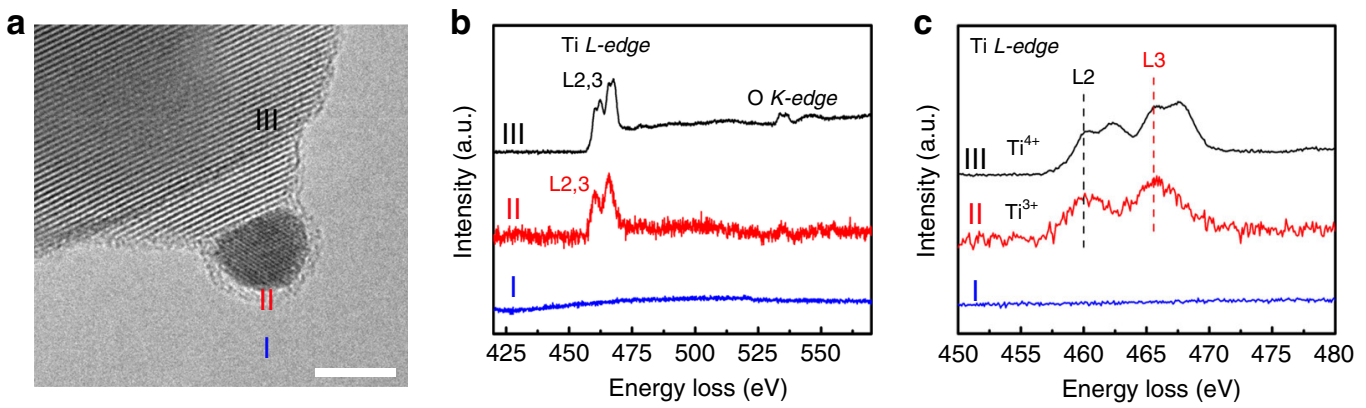

Fig. 2 Electron Energy Loss Spectroscopy analysis. a HRTEM image of Au/TiO ${ }_{2} @ M-N-800$. b and c Fitted EELS spectra from 450 to 480 eV. The spectra were background-subtracted. The scale bar corresponds to $5 \mathrm{~nm}$. Additional EELS results can be found in Supplementary Figs. 6-8.

$\mathrm{Au} / \mathrm{TiO}_{2} @ \mathrm{M}-\mathrm{N}, \mathrm{Au} / \mathrm{TiO}_{2} @ \mathrm{M}-\mathrm{N}-800$ and $\mathrm{Au} / \mathrm{TiO}_{2}-800$, especially for the last two. Furthermore, the crystal structure of $\mathrm{TiO}_{2}$ was also analyzed (Supplementary Table 1). And anatase was identified as the primary phase for $\mathrm{Au} / \mathrm{TiO}_{2}, \mathrm{Au} / \mathrm{TiO}_{2} @ \mathrm{M}$ and $\mathrm{Au} / \mathrm{TiO}_{2} @ \mathrm{M}-\mathrm{N}$. After calcination at $800^{\circ} \mathrm{C}$, anatase transformed to rutile completely in $\mathrm{Au} / \mathrm{TiO}_{2}-800$. However, for $\mathrm{Au} / \mathrm{TiO}_{2} @ \mathrm{M}-$ $\mathrm{N}-800$ sample $12 \%$ anatase still existed, implying the phase conversion from anatase to rutile was delayed in a degree. The inhibition may be ascribed to the enhanced interaction between $\mathrm{Au}$ and support, in line with the recent reports ${ }^{23}$.

To identify the chemical composition of the cover layer in $\mathrm{Au} /$ $\mathrm{TiO}_{2} @ \mathrm{M}-\mathrm{N}-800$, the sample was probed by electron energy loss spectroscopy (EELS). Figure $2 \mathrm{~b}$ and Supplementary Fig. 6b showed the obvious Ti L-edge signals in the amorphous overlayer, demonstrating the encapsulation by Ti-containing coating. While no $\mathrm{C}$ or $\mathrm{N}$ signal was observed in the overlayer region, proving the composition of overlayer was pure $\mathrm{TiO}_{x}$ (Supplementary Figs. 7, 8). (Note: The signals of $\mathrm{C}$ and $\mathrm{N}$ in EELS are located at 280 and $400 \mathrm{eV}$, respectively). On the other hand, N $1 s$ XPS spectra in $\mathrm{Au} / \mathrm{TiO}_{2} @ \mathrm{M}$ definitely demonstrated that melamine was adsorbed on the $\mathrm{Au} / \mathrm{TiO}_{2}$ (Supplementary Fig. 9). And a decrease of N 1s XPS intensity in $\mathrm{Au} / \mathrm{TiO}_{2} @ \mathrm{M}-\mathrm{N}$ may be ascribed to the carbonization of melamine and no N $1 s$ XPS signal was observed in $\mathrm{Au} / \mathrm{TiO}_{2} @ \mathrm{M}-\mathrm{N}-800$ which demonstrated melamine had decomposed completely. The EELS results also revealed that $\mathrm{Ti}$ species on the overlayer existed as $\mathrm{Ti}^{3+}$ oxidation state (region II) while those on the support were $\mathrm{Ti}^{4+}$ oxidation state (region III), respectively, in consistent with the previous reports (Fig. 2c and Supplementary Fig. $6 c)^{28,46,55}$. However, no reduced $\mathrm{Ti}^{3+}$ species were observed in the Ti $2 p$ XPS spectra (Supplementary Fig. 10), in contrast to the case of classical SMSI, may be due to the smaller number of $\mathrm{TiO}_{x}$ species $^{51,56}$. The EELS analysis of Au/ $\mathrm{TiO}_{2} @ \mathrm{M}-\mathrm{N}-800$ catalyst definitely demonstrated the existence and the composition of the overlayer on Au NPs. To the best of our knowledge, this phenomenon has never been reported before as it was well-recognized that Au NPs can only be encapsulated by $\mathrm{TiO}_{\mathrm{x}}$ in reductive condition at high temperature (classical SMSI), inconsistent with the condition in this work ${ }^{28,37-39}$.

Changes of Au structure during treatments. To determine if there is adsorption change and/or electron transfer between gold and support, in situ diffuse reflectance infrared Fourier transform spectroscopy (DRIFTS) measurements of CO adsorption were examined. As shown in Fig. 3, two bands were detected on $\mathrm{Au} /$ $\mathrm{TiO}_{2}$ at 2174 and $2104 \mathrm{~cm}^{-1}$, respectively. The former was ascribed to gaseous $\mathrm{CO}$ as the peak decreased rapidly and disappeared totally under purge with He (Supplementary Fig. 11a, b). The latter was due to $\mathrm{CO}$ adsorbed on metallic $\mathrm{Au} \mathrm{NPs}^{57}$. When modification with melamine, $\mathrm{CO}$ absorption band red-shifted to $2098 \mathrm{~cm}^{-1}$ assigned to $\mathrm{Au}^{\delta-}$ and accompanied by a decrease in

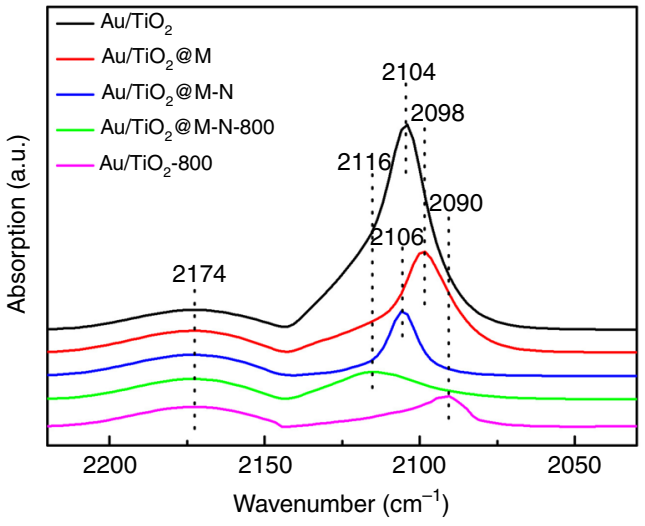

Fig. 3 DRIFTS analysis. In situ DRIFT spectra of $\mathrm{CO}$ adsorption on $\mathrm{Au} /$ $\mathrm{TiO}_{2}, \mathrm{Au} / \mathrm{TiO}_{2} @ \mathrm{M}, \mathrm{Au} / \mathrm{TiO}_{2} @ \mathrm{M}-\mathrm{N}, \mathrm{Au} / \mathrm{TiO}_{2} @ \mathrm{M}-\mathrm{N}-800$, and $\mathrm{Au} / \mathrm{TiO}_{2}-$ 800 .

intensity. The red-shift of $\mathrm{CO}$ adsorption may be due to the electron transfer from melamine to $\mathrm{Au}$ and therefore the adsorption intensity decreased, as it was difficult for CO to adsorb on $\mathrm{Au}^{\delta-}$ and there was no change in the structure morphology of $\mathrm{Au} \mathrm{NPs}{ }^{28}$. However, after pretreatment at $600^{\circ} \mathrm{C}$ in $\mathrm{N}_{2}$ flow, 2098 $\mathrm{cm}^{-1}$ band was blue-shifted to $2106 \mathrm{~cm}^{-1}$ and accompanied by a decrease in intensity. The blue-shift of $\mathrm{CO}$ adsorption band may be attributed to electron withdrawing from Au NPs to melamine due to the carbonization of melamine. Furthermore, the decrease of the intensity may be ascribed to the particle size increase. After being subjected to calcination at $800{ }^{\circ} \mathrm{C}, 2106 \mathrm{~cm}^{-1}$ adsorption band blue-shifted to $2116 \mathrm{~cm}^{-1}$, suggesting much more positive charge on the surface Au species, which may be attributed to the electron transfer from Au NPs to $\mathrm{TiO}_{2}$ support as melamine had decomposed completely at this high temperature. It is noteworthy that $2116 \mathrm{~cm}^{-1}$ is not the band of gas-phase $\mathrm{CO}$ as it still existed under purge with $\mathrm{He}$ while gaseous $\mathrm{CO}$ band $\left(2174 \mathrm{~cm}^{-1}\right)$ decreased rapidly after $30 \mathrm{~s}$ and disappeared completely within 2 min (Supplementary Fig. 11c, d), suggesting that this band is the peak of $\mathrm{CO}$ adsorption on $\mathrm{Au}^{\delta+}$ as $\mathrm{CO}-\mathrm{Au}^{\delta+}$ is quite stable $e^{53,58}$. The intensity decrease can be ascribed to the loss of $\mathrm{CO}$ adsorption sites resulting from the encapsulation of Au NPs by $\mathrm{TiO}_{x}$ instead of sintering of the Au NPs as the mean size of $\mathrm{Au}$ NPs only increased from 6.7 to $7.5 \mathrm{~nm}$, in good consistent with high-resolution transmission electron microscopy (HRTEM) results. Comparatively, the adsorption band at $2090 \mathrm{~cm}^{-1}$ and loss $\mathrm{CO}$ adsorption were observed for $\mathrm{Au} / \mathrm{TiO}_{2}-800$, which was ascribed to the serious sintering of Au NPs leading to the decrease of adsorption sites, consistent with HRTEM results. The red-shift was due to the decrease of the positively charged Au species, in accordance with previous report ${ }^{27}$. While no obvious changes in 

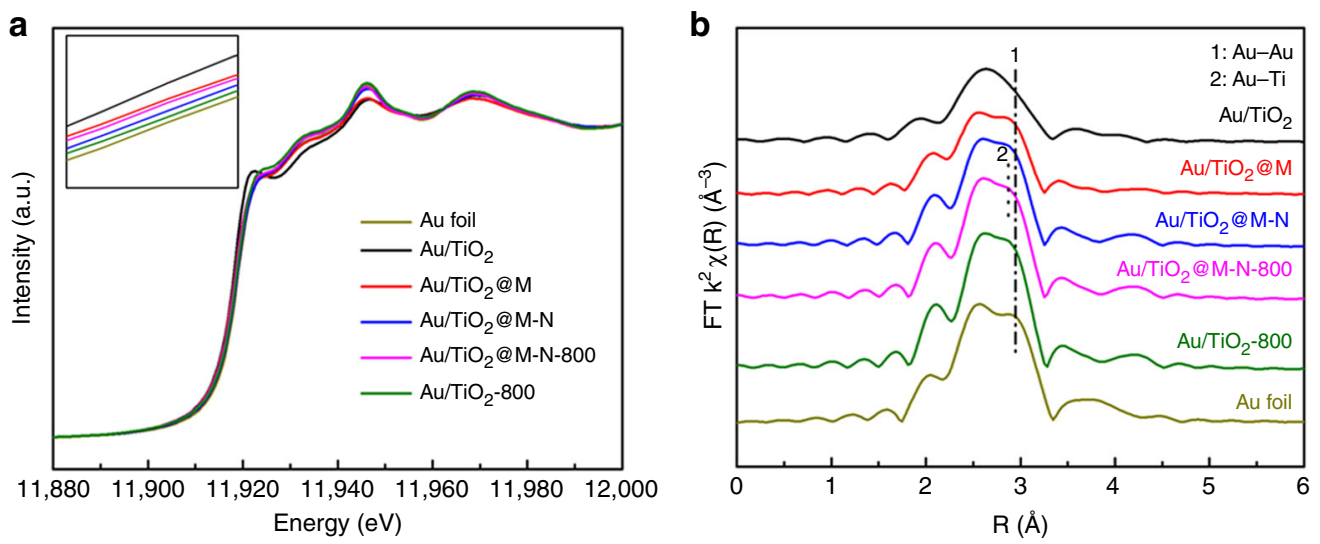

Fig. 4 X-ray absorption spectroscopy analysis. a Normalized XANES spectra at the Au LIII-edge of Au foil, Au/TiO $, A u / T i O_{2} @ M, A u / T i O_{2} @ M-N, A u /$ $\mathrm{TiO}_{2} @ \mathrm{M}-\mathrm{N}-800, \mathrm{Au} / \mathrm{TiO}_{2}-800$. b Fourier transform of $k^{3}$-weighted EXAFS spectra of Au foil, Au/TiO $2, A u / T i \mathrm{~T}_{2} @ \mathrm{M}, \mathrm{Au} / \mathrm{TiO} \mathrm{O}_{2} @ \mathrm{M}-\mathrm{N}, \mathrm{Au} / \mathrm{TiO} \mathrm{O}_{2} @ \mathrm{M}-\mathrm{N}-$ 800 , and $\mathrm{Au} / \mathrm{TiO}_{2}-800$.

the binding energy of Au $4 f$ were observed, suggesting that melamine treatment and subsequent calcinations did not affect the oxidation state of the surface Au significantly (Supplementary Fig. 12).

To further investigate the interaction between $\mathrm{Au}$ NPs and $\mathrm{TiO}_{2}, \mathrm{Au} \mathrm{L} \mathrm{L}_{\mathrm{III}}$-edge XAFS spectra were collected on a series of samples to follow the coordination environment and valence state of the gold. As displayed in Fig. 4a, we showed the normalized $\mathrm{Au}$ $\mathrm{L}_{\mathrm{III}}$-edge XANES spectra recorded on a series of $\mathrm{Au} / \mathrm{TiO}_{2}$ samples. The white line intensity was much stronger for $\mathrm{Au} / \mathrm{TiO}_{2}$ and $\mathrm{Au} /$ $\mathrm{TiO}_{2} @ \mathrm{M}$ than other samples, which was ascribed to the presence $\mathrm{Au}^{3+59}$. Moreover, the white line intensity of $\mathrm{Au} / \mathrm{TiO}_{2} @ \mathrm{M}-\mathrm{N}-800$ was stronger than $\mathrm{Au} / \mathrm{TiO}_{2} @ \mathrm{M}-\mathrm{N}$ and $\mathrm{Au} / \mathrm{TiO}_{2}-800$, indicating much more positive charge on the gold. In the Fourier transforms of $k^{3}$-weighted EXAFS oscillations (Fig. 4b), a two-shells fitting was performed. In the first shell, the coordination number of $\mathrm{Au}-$ Aul increased from 5.9 to 8.4 and the average bond length of $\mathrm{Au}-$ Aul increased from 2.82 to $2.85 \AA$ when the pretreatment temperature increased from 250 to $800{ }^{\circ} \mathrm{C}$. While for $\mathrm{Au} / \mathrm{TiO}_{2}$ 800 the coordination number and the average bond length of $\mathrm{Au}$ Aul were 9.8 and $2.86 \AA$, respectively, which was much closer to that of $\mathrm{Au}$ foil that suggested the $\mathrm{d}$ orbital of $\mathrm{Au}$ was almost entirely occupied, in good accordance with the XANES results. Moreover, it was found that including additional $\mathrm{Au}-\mathrm{O}$ shells would lower the quality of fitting results, which may be ascribed to the growth of the Au NPs size. Furthermore, a two-shell analysis of the narrow window region data of $\mathrm{Au} / \mathrm{TiO}_{2} @ \mathrm{M}-\mathrm{N}-800$ using $\mathrm{Au}-\mathrm{Au}$ and $\mathrm{Au}-\mathrm{Ti}$ scattering parameters gave a good fitting result. The best fitting was obtained with Au-Aul bond distance of 2.85 $\AA(N=8.4)$ and $\mathrm{Au}-\mathrm{Ti}$ bond distance of $2.79 \AA(N=5.6)$. The expected $\mathrm{Au}-\mathrm{Ti}$ distance of $2.79 \AA$ was similar to that of $\mathrm{AuTi}$ alloy phase ${ }^{60}$. The fitting results were summarized in Supplementary Table 2 and the $k$-space curves were depicted in Supplementary Fig. 13. And the previous studies on $\mathrm{Pt} / \mathrm{TiO}_{2}$ and $\mathrm{Rh} / \mathrm{TiO}_{2}$ catalysts in the SMSI state provided direct evidence for Pt-Ti bond and $\mathrm{Rh}-\mathrm{Ti}$ bond with a distance of 2.76 and $2.56 \AA$, respectively ${ }^{61,62}$. Therefore, there was no doubt that the encapsulation state leaded to a structural reorganization of the $\mathrm{TiO}_{2}$ support in the neighborhood of the Au NPs. And this reorganization of the support only generated where there was Au NPs and encapsulation occurred. Otherwise, no reorganization would occur.

Catalytic performance in a series of reactions. CO oxidation was performed as a typical probe reaction due to its great importance in fundamental study, especially its size-dependent behavior ${ }^{63}$. As shown in Fig. $5 \mathrm{a}, \mathrm{Au} / \mathrm{TiO}_{2}$ revealed the highest activity with a $\mathrm{T} 50$ (the temperature $50 \%$ conversion is acquired) of $-2.1^{\circ} \mathrm{C}$. After calcination at $800^{\circ} \mathrm{C}, \mathrm{Au} / \mathrm{TiO}_{2} @ \mathrm{M}-\mathrm{N}-800$ exhibited a much higher activity compared with $\mathrm{Au} / \mathrm{TiO}_{2}-800$, explicitly displaying the strong effect of particle size on catalytic performance. According to the active curve, the T50 was determined to be $32^{\circ} \mathrm{C}$ for $\mathrm{Au} / \mathrm{TiO}_{2} @ \mathrm{M}-\mathrm{N}-800$. While for $\mathrm{Au} / \mathrm{TiO}_{2}-800$ the activity was negligible below $220^{\circ} \mathrm{C}$ with a T50 of $245^{\circ} \mathrm{C}$. On the basis of TEM and DRIFTS characterization results, the poor activity of $\mathrm{Au} / \mathrm{TiO}_{2}-800$ was attributed to the serious sintering of $\mathrm{Au}$ NPs. However, for $\mathrm{Au} / \mathrm{TiO}_{2} @ \mathrm{M}-\mathrm{N}-800$ it was due to the encapsulation of $\mathrm{Au}$ by $\mathrm{TiO}_{\mathrm{x}}$ overlayer leading to the partial decrease of accessible active sites. To investigate the kinetic study of the above catalysts, the specific reaction rates and turn over frequency (TOF) were determined at $25^{\circ} \mathrm{C}$. For $\mathrm{Au} / \mathrm{TiO}_{2}$ catalyst, the reaction rate and TOF were $0.536 \mathrm{~mol}_{\mathrm{CO}} \mathrm{h}^{-1} \mathrm{~g}_{\mathrm{Au}}{ }^{-1}$ and $0.12 \mathrm{~s}^{-1}$, respectively, in good accordance with the above results. While for $\mathrm{Au} / \mathrm{TiO}_{2} @ \mathrm{M}-\mathrm{N}-800$, the reaction rate was induced by a 3 -fold decrease from 0.536 to $0.186 \mathrm{~mol}_{\mathrm{CO}} \mathrm{h}^{-1} \mathrm{~g}_{\mathrm{Au}}{ }^{-1}$. As for $\mathrm{Au} / \mathrm{TiO}_{2^{-}}$ 800, the sintering of $\mathrm{Au}$ NPs decreased the reaction rate by about 90-fold from 0.536 to $0.006 \mathrm{~mol}_{\mathrm{CO}} \mathrm{h}^{-1} \mathrm{~g}_{\mathrm{Au}}{ }^{-1}$.

Furthermore, the activity of the $\mathrm{Au} / \mathrm{TiO}_{2} @ \mathrm{M}-\mathrm{N}-800$ was also compared with that of $\mathrm{Au} / \mathrm{TiO}_{2}$ catalysts in classical SMSI state before and after calcination. It was showed that the T50 of $\mathrm{Au} /$ $\mathrm{TiO}_{2}-\mathrm{H} 500$ and $\mathrm{Au} / \mathrm{TiO}_{2}-\mathrm{H} 500-\mathrm{O} 400$ were -19.5 and $16.5^{\circ} \mathrm{C}$ and the corresponding particle size were about 3.2 and $4.2 \mathrm{~nm}$, respectively (Supplementary Figs. 14-16). HRTEM results showed that $\mathrm{Au}$ NPs were encapsulated with a $\mathrm{TiO}_{x}$ overlayer in $\mathrm{Au} / \mathrm{TiO}_{2}-\mathrm{H} 500$, which retreated after further calcination under oxidation condition, consistent with our previous report ${ }^{28}$. It should be noted that the $\mathrm{TiO}_{x}$ overlayer in classical SMSI was much thinner than the overlayer induced by melamine in this work. After calcination at $800^{\circ} \mathrm{C}$ in air for $3 \mathrm{~h}$, the T50 of Au/ $\mathrm{TiO}_{2}-\mathrm{H} 500-800$ and $\mathrm{Au} / \mathrm{TiO}_{2}-\mathrm{H} 500-\mathrm{O} 400-800$ were 191 and $168^{\circ} \mathrm{C}$ and the particle size were 28.6 and $27.2 \mathrm{~nm}$, respectively, in which no overlayer was observed and Au NPs sintered seriously (Supplementary Figs. 17, 18). Therefore, the overlayer formed in the reduction condition retreated under oxidation condition (classical SMSI) may account for the sintering of $\mathrm{Au}$ in $\mathrm{Au} / \mathrm{TiO}_{2}-\mathrm{H} 500-800$, leading to invalid effect on the catalytic and stability property of the underlying metal. And the T50 of $\mathrm{Au} /$ $\mathrm{TiO}_{2} @ \mathrm{M}-\mathrm{N}-800$ was much lower than that of $\mathrm{Au} / \mathrm{TiO}_{2}-$ H500-800, exhibiting the excellent sintering-resistant ability and superiority of $\mathrm{Au} / \mathrm{TiO}_{2} @ \mathrm{M}-\mathrm{N}-800$ compared with $\mathrm{Au} /$ $\mathrm{TiO}_{2}-\mathrm{H} 500-800$. For comparison, the specific rate and/or TOF of the above the catalysts and some reported catalysts are listed in 

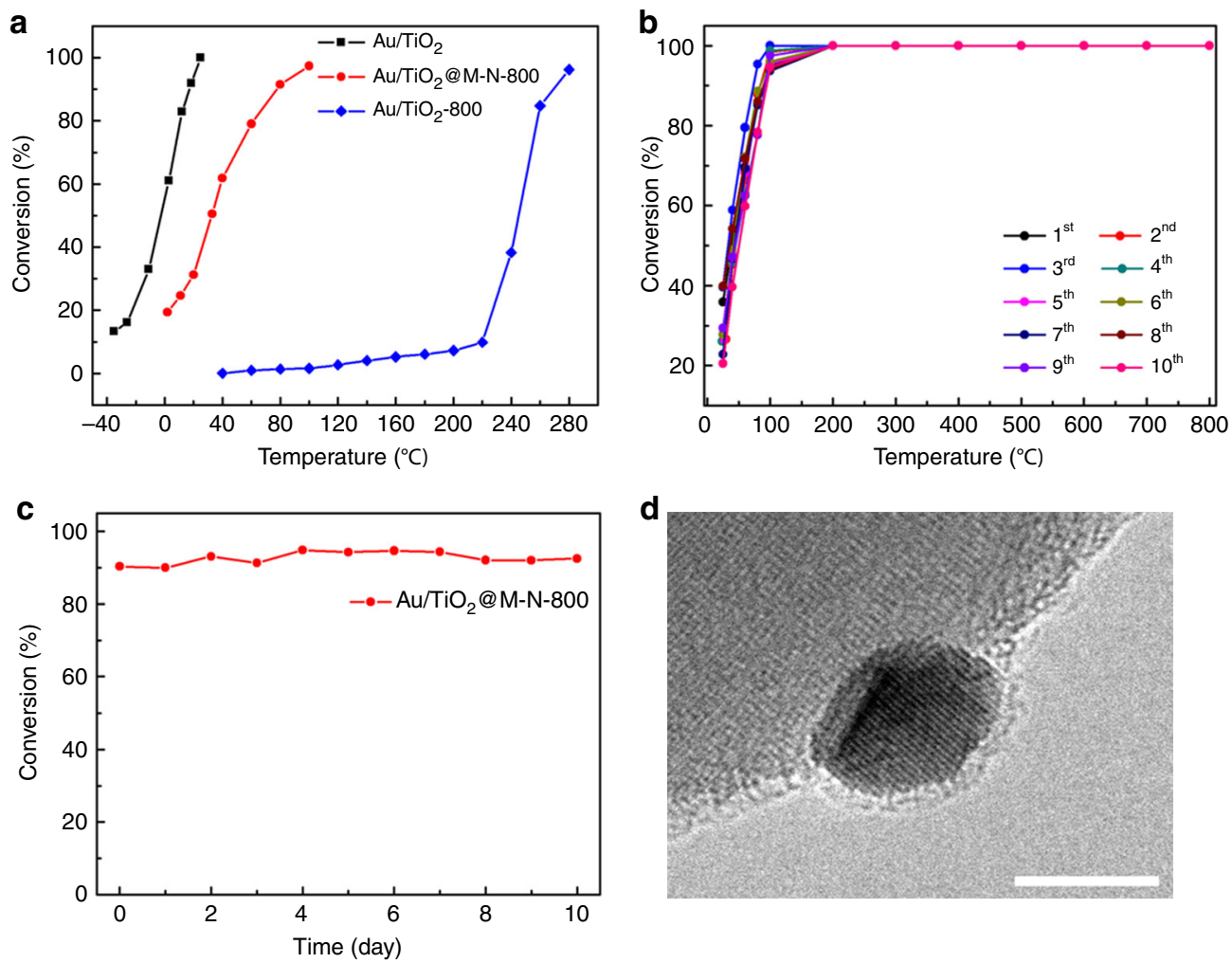

Fig. 5 Evaluation of $\mathbf{A u} / \mathrm{TiO}_{2}$ nanocatalysts in $\mathbf{C O}$ oxidation and simulated $\mathbf{C O}$ emission control reaction. a $\mathrm{CO}$ oxidation curves of $\mathrm{Au} / \mathrm{TiO} \mathrm{O}_{2}, \mathrm{Au} /$ $\mathrm{TiO}_{2} @ \mathrm{M}-\mathrm{N}-800$ and $\mathrm{Au} / \mathrm{TiO}_{2}-800$ with a feed gas comprising 1 vol\% $\mathrm{CO} / 1 \mathrm{vol} \% \mathrm{O}_{2} / 98$ vol\% $\mathrm{He}$ at $33.3 \mathrm{~mL} \mathrm{~min}^{-1}$. b Conversion of $\mathrm{CO}$ from 0 to $800{ }^{\circ} \mathrm{C}$ with 1st-10th cycles on Au/ $\mathrm{TiO}_{2} @ \mathrm{M}-\mathrm{N}-800$ catalyst for ten ignition-extinction cycles with a feed gas comprising 1 vol\% $\mathrm{CO} / 1$ vol\% $\mathrm{O}_{2} / 98$ vol\% $\mathrm{He}$ at 33.3 $\mathrm{mL} \mathrm{min}{ }^{-1}$. c Long-term simulated CO emission control reaction at $400^{\circ} \mathrm{C}$ on the Au/ $\mathrm{TiO}_{2} @ \mathrm{M}-\mathrm{N}-800$ with space velocity of $220 \mathrm{~L} \mathrm{~h}^{-1} \mathrm{~g}_{\text {cat }}{ }^{-1}$. Reaction gas composition: 1.6 vol\% CO, 1 vol\% $\mathrm{O}_{2}, 0.01$ vol\% propene, 0.00852 vol\% toluene, 10 vol\% water and balanced with He. d HRTEM image of Au/TiO $@$ @M-N800 after simulated $\mathrm{CO}$ emission control reaction at $400^{\circ} \mathrm{C}$ for 10 days. The scale bar corresponds to $5 \mathrm{~nm}$.

Supplementary Table 3. To the best of our knowledge, it is the first time to report that Au NPs can be encapsulated by titania under oxidative atmosphere at high temperature, in contrast with condition required for classical SMSI. Although the resultant $\mathrm{Au} /$ $\mathrm{TiO}_{2} @ \mathrm{M}-\mathrm{N}-800$ does not outperform the state-of-the-art, it is still comparable to the $\mathrm{Au} / \mathrm{TiO}_{2}-\mathrm{HAP}-800$ and $\mathrm{Au} / \mathrm{TiO}_{2}-\mathrm{SiO}_{2}-800$ catalysts, which are the most excellent sintering-resistance catalyst up to now.

The reaction stability of $\mathrm{Au} / \mathrm{TiO}_{2} @ \mathrm{M}-\mathrm{N}-800$ catalyst was tested with $\mathrm{CO}$ oxidation at $400{ }^{\circ} \mathrm{C}$ with a high space velocity of $500 \mathrm{~L} \mathrm{~h}^{-1}$ $\mathrm{g}_{\mathrm{cat}}{ }^{-1}$. As shown in Supplementary Fig. 19, the conversion increased from 79.1 to $90.1 \%$ during $100 \mathrm{~h}$ test instead of deactivation, demonstrating the excellent sintering-resistance and stability. HRTEM images of the used Au/TiO ${ }_{2} @ M-N-800$ catalyst proved that the overlayer was still covering Au NPs, explaining the distinguished stability (Supplementary Fig. 20c, d). And the increase of the activity during the reaction may be due to much more active sites were accessible, as the overlayer on the used catalyst was not so dense compared with the fresh catalyst (Supplementary Fig. 20e, f). The recycle performance of $\mathrm{Au} / \mathrm{TiO}_{2} @ \mathrm{M}-\mathrm{N}-800$ was also examined by successive 10 ignition-extinction cycles up to $800^{\circ} \mathrm{C}$. Figure $5 \mathrm{~b}$ displayed that the catalyst exhibited a slight decrease of the activity after 10th cycles. HRTEM images of the used Au/TiO $\mathrm{T}_{2} @ \mathrm{M}-\mathrm{N}-800$ catalyst demonstrated that $\mathrm{TiO}_{\mathrm{x}}$ overlayer still existed on the $\mathrm{Au}$ NPs which afforded the sinter-resistant Au nanocatalyst (Supplementary Fig. 21). And it has been acknowledged that water would expedite the sintering of Au NPs. Therefore, water-gas shift (WGS) reaction was performed on $\mathrm{Au} / \mathrm{TiO}_{2} @ \mathrm{M}-\mathrm{N}-800$ catalyst at $500{ }^{\circ} \mathrm{C}$ with space velocity of $18 \mathrm{~L} \mathrm{~h}^{-1} \mathrm{~g}_{\mathrm{cat}}{ }^{-1}$. As expected, the conversion almost kept at $45 \%$ during the $90 \mathrm{~h}$ test, further certifying the excellent stability of $\mathrm{Au} / \mathrm{TiO}_{2} @ \mathrm{M}-\mathrm{N}-800$ catalyst (Supplementary Fig. 22). TEM image of the used $\mathrm{Au} / \mathrm{TiO}_{2} @ \mathrm{M}-\mathrm{N}-800$ catalyst exhibited that the particle size of Au NPs remained unchanged. HRTEM images demonstrated that the $\mathrm{Au}$ NPs were still encapsulated by $\mathrm{TiO}_{x}$ overlayer after reaction, leading to ultrastable $\mathrm{Au}$ NPs (Supplementary Fig. 23). To further evaluate the stability of $\mathrm{Au} / \mathrm{TiO}_{2} @ \mathrm{M}-\mathrm{N}-800$ in presence of water and other gases, simulated $\mathrm{CO}$ emission control was performed at $400{ }^{\circ} \mathrm{C}$ with the feed mixture gas containing $1.6 \mathrm{vol} \% \mathrm{CO}, 1 \mathrm{vol} \% \mathrm{O}_{2}, 0.01$ vol\% propene, 0.00852 vol\% toluene, $10 \mathrm{vol} \%$ water and balanced with He. Figure $5 \mathrm{c}$ showed that $\mathrm{CO}$ conversion of $\mathrm{Au} / \mathrm{TiO}_{2} @ \mathrm{M}-\mathrm{N}-800$ increased from $90.3 \%$ to $92.5 \%$ during the test for 10 days, exhibiting an excellent durability. TEM image of the used $\mathrm{Au} / \mathrm{TiO}_{2} @ \mathrm{M}-\mathrm{N}-800$ catalyst showed that the mean size of Au NPs was $7.3 \mathrm{~nm}$, almost similar with the fresh catalyst (Supplementary Fig. 24a, b). HRTEM images (Fig. 5d and Supplementary Fig. 24c) revealed the still existence of the $\mathrm{TiO}_{\mathrm{x}}$ overlayer on the Au NPs after reaction for 10 days, which meant that water and other gases in the reaction almost had no influence on the $\mathrm{TiO}_{\mathrm{x}}$ overlayer. And the increase of the activity during the reaction may be due to much more accessible active sites (Supplementary Fig. 24d-f). However, for the catalyst without the encapsulation, the reactivity decreased continuously because of the aggregation of $\mathrm{Au} \mathrm{NPs}{ }^{27,30}$. Therefore, the encapsulation of $\mathrm{Au}$ by $\mathrm{TiO}_{x}$ cover layer plays a crucial role in influencing the catalytic performances.

Relating encapsulation induced by melamine to SMSI behavior. In above, we have demonstrated the encapsulation of $\mathrm{Au}$ NPs by $\mathrm{TiO}_{x}$ overlayer under oxidative condition induced by 


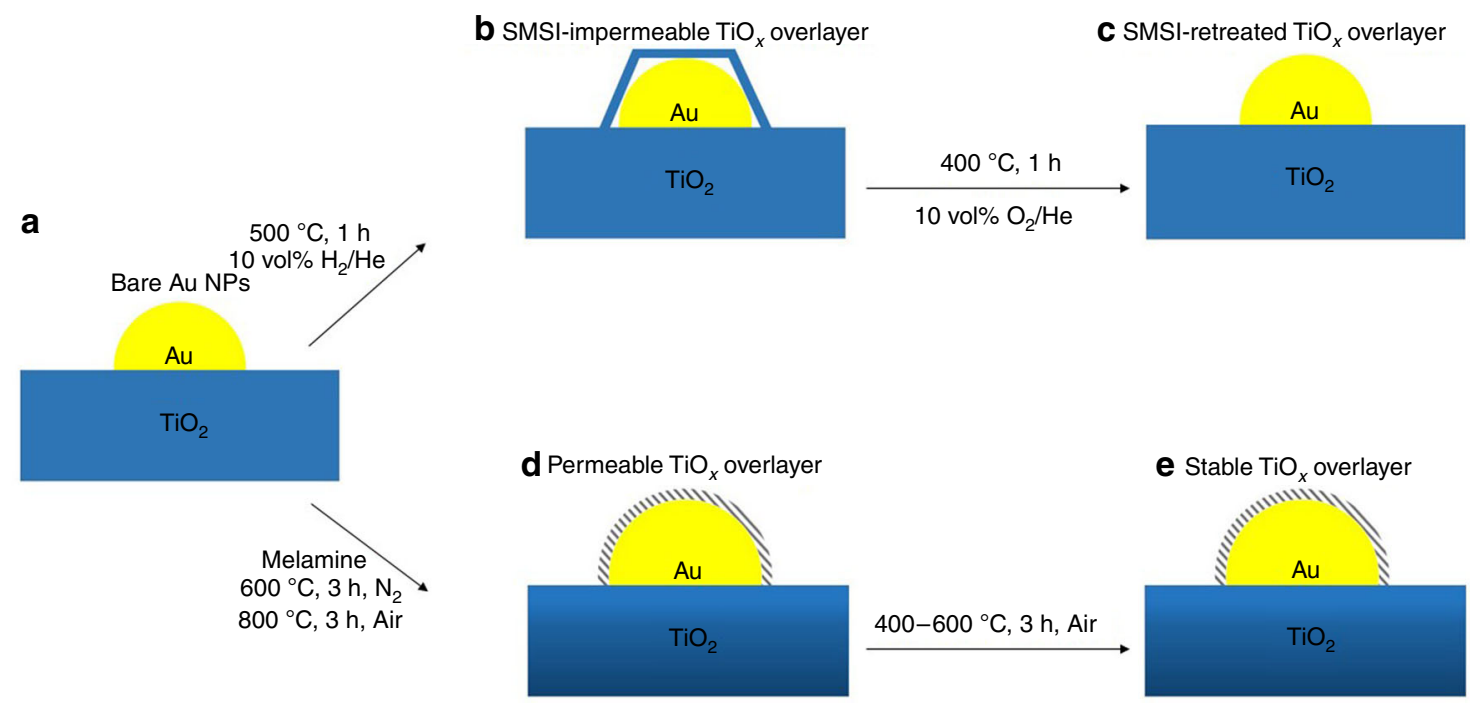

Fig. 6 SMSI and melamine-induced $\mathrm{TiO}_{\mathbf{x}}$ overlayer structure and behavior. a Bare Au nanoparticles on $\mathrm{TiO}_{2}$. $\mathbf{b} \mathrm{Au} / \mathrm{TiO}_{2}$ catalyst that forms an impermeable SMSI $\mathrm{TiO}_{x}$ overlayer after treatment with 10 vol\% $\mathrm{H}_{2} / \mathrm{He}$ at $500^{\circ} \mathrm{C}$. c SMSI TiO $\mathrm{S}_{x}$ overlayer retreats when exposed to oxidation condition at $400^{\circ} \mathrm{C}$ which is almost similar with that in a. d Melamine-modified catalyst that forms a permeable $\mathrm{TiO}_{x}$ overlayer after treatment with $\mathrm{N}_{2}$ at high temperature $\left(600^{\circ} \mathrm{C}\right)$ followed by treatment with air at $800^{\circ} \mathrm{C}$. e Stable melamine-induced $\mathrm{TiO}_{x}$ overlayer under air condition modifies the Au NPs catalytic bahavior.

melamine while high temperature reduction pretreatment is prerequisite for the encapsulation of $\mathrm{Au} \mathrm{NPs}_{\text {by }} \mathrm{TiO}_{x}$ in classical SMSI. Furthermore, this kind of encapsulation may not belong to classical SMSI as the mean size of the Au NPs increases from 3.5 to $7.5 \mathrm{~nm}$ while the mean diameter of $\mathrm{Au}$ NPs remains almost unchanged in classical SMSI. Therefore, the formation mechanisms of these two kinds of overlayer are different. The formation process of classical SMSI overlayer and melamine-induced $\mathrm{TiO}_{x}$ overlayer can be illustrated by Fig. 6 . To investigate whether the overlayer will recede, $\mathrm{Au} / \mathrm{TiO}_{2} @ \mathrm{M}-\mathrm{N}-800$ sample was further calcined in air atmosphere at $400{ }^{\circ} \mathrm{C}, 500^{\circ} \mathrm{C}$ and $600{ }^{\circ} \mathrm{C}$ for $3 \mathrm{~h}$, respectively. HRTEM results showed that $\mathrm{Au}$ NPs were still encapsulated by $\mathrm{TiO}_{x}$ overlayer, which was different from classical SMSI in which $\mathrm{TiO}_{x}$ overlayer will retreat under further heating in oxidation condition (Supplementary Figs. 25-27) 28,37,38,55. Moreover, the encapsulation $\mathrm{TiO}_{x}$ overlayer induced by melamine is porous and permeable to reactant and very stable under oxidative reaction condition, which may minimize the reactants diffusion on $\mathrm{Au}$ surface and strongly enhance the sinteringresistance and catalytic performance of the Au.

As shown in Fig. 1c and Supplementary Fig. 28, encapsulation did not occur when calcination in $\mathrm{N}_{2}$ flow at $600^{\circ} \mathrm{C}$. And no cover layer was observed even calcination in $\mathrm{N}_{2}$ at $800^{\circ} \mathrm{C}$ (Supplementary Fig. 29), which indicated that encapsulation could not occur only calcination in $\mathrm{N}_{2}$ follow. As displayed in Supplementary Figs. 30-31, when $\mathrm{Au} / \mathrm{TiO}_{2} @ \mathrm{M}$ sample was heated directly in air at 600 or $800{ }^{\circ} \mathrm{C}$ without pretreatment in $\mathrm{N}_{2}$ atmosphere no overlayer was observed, suggesting the indispensable of pretreatment in $\mathrm{N}_{2}$. Supplementary Figs. 32-33 showed that overlayer also could not be formed when calcination in air at 500 or $600{ }^{\circ} \mathrm{C}$ after pretreatment in $\mathrm{N}_{2}$, which meant higher anneal temperature was requisite. For $\mathrm{Au} / \mathrm{TiO}_{2}$ catalyst without modification with melamine and pretreatment under similar condition with that of $\mathrm{Au} / \mathrm{TiO}_{2} @ \mathrm{M}-\mathrm{N}-800$ (denoted as $\left.\mathrm{Au} / \mathrm{TiO}_{2}-\mathrm{N}-800\right)$, no cover layer was observed instead of the sintering of $\mathrm{Au}$ NPs, indicating the significant role of melamine in the formation of $\mathrm{TiO}_{\mathrm{x}}$ overlayer (Supplementary Fig. 34). To identify whether the encapsulation can be extended to other related materials, two catalysts (denoted as Au/anatase@M-N-800 and Au/rutile@M-N-800) were prepared with the same method as $\mathrm{Au} / \mathrm{TiO}_{2} @ \mathrm{M}-\mathrm{N}-800$. As shown in Supplementary Figs. 35-36, a $\mathrm{TiO}_{\mathrm{x}}$ overlayer was observed on both catalysts, evidencing a common encapsulation phenomenon between $\mathrm{Au}$ and theses two titania supports. Moreover, similar encapsulations can also be obtained on colloidal $\mathrm{Au}$ NPs supported on $\mathrm{TiO}_{2}$ (denoted as $\left.\mathrm{C}-\mathrm{Au} / \mathrm{TiO}_{2} @ \mathrm{M}-\mathrm{N}-800\right)$ and commercial gold catalyst RR2Ti (denoted as RR2Ti@M-N-800), suggesting the universality of this strategy and providing a widespread way which enables to rationally design sintering-resistant gold catalysts via $\mathrm{TiO}_{x}$ overlayer encapsulation strategy (Supplementary Figs. 37-38).

It is worth to summarize the mechanism and the effect of adsorbate melamine on the formation of the $\mathrm{TiO}_{x}$ overlayer and stabilization of Au NPs. The HRTEM and EELS results verify the role of melamine in mediating $\mathrm{TiO}_{x}$ overlayer formation. On the basis of identification $\mathrm{Ti}^{3+}$ in the cover layer by EELS, we hypothesize the plausible mechanism is that electron is transferred from $\mathrm{Au}$ NPs to $\mathrm{TiO}_{2}$ under the effect of melamine at high annealing temperature under oxidative condition, leading to the reduction of $\mathrm{Ti}^{4+}$ to $\mathrm{Ti}^{3+}$ and partial positive charge on gold, in consistent with DRIFTS results. Meanwhile, EXAFS fitting results corroborate the presence of $\mathrm{Au}-\mathrm{Ti}$ bond in the encapsulation state, which may lead to the migration of titania onto $\mathrm{Au}$ NPs thermodynamically favorable ${ }^{46,56}$, similar with classical SMSI in which Pt-Ti and Rh-Ti bond are observed after high temperature reduction pretreatment. However, the specific effect of melamine in electron transfer is still unclear and much more work is deserved to be done. And further research is also required to clarify the real driving force for this kind of encapsulation.

\section{Discussion}

In summary, we have presented an ultrastable titania-supported $\mathrm{Au}$ nanocatalyst in which $\mathrm{Au}$ NPs were encapsulated with a permeable $\mathrm{TiO}_{x}$ overlayer mediated by melamine under oxidative atmosphere. The indispensable pretreatment condition is anneal in $\mathrm{N}_{2}$ flow and further calcination at $800^{\circ} \mathrm{C}$ under air condition, in contrast with classical SMSI which occurs under reductive condition. And the overlayer is stable even further calcination under oxidative condition, which is contrary to classical SMSI. 
Owing to the formation of permeable and stable $\mathrm{TiO}_{x}$ layer, the designed catalyst is sintering-resistant with high catalytic activity and excellent durability. In addition, this methodology can be extended to colloidal Au catalyst and even commercial RR2Ti catalyst. More importantly, this work paves a new avenue for designing sintering-resistant Au nanocatalysts with high activity via $\mathrm{TiO}_{x}$ overlayer encapsulation strategy.

\section{Methods}

Synthesis of $\mathbf{A u} / \mathrm{TiO}_{\mathbf{2}}$. As a typical run, $\mathrm{Au} / \mathrm{TiO}$ was synthesized with the DP method. A $40 \mathrm{~mL}$ of $\mathrm{HAuCl}_{4} \cdot 4 \mathrm{H}_{2} \mathrm{O}$ aqueous solution $\left(6.3 \mathrm{mmol} \mathrm{L}^{-1}\right)$ was adjusted to PH 9.0 with $0.1 \mathrm{M} \mathrm{NaOH}$. Then, $1 \mathrm{~g}$ of $\mathrm{TiO}_{2}$ (Degussa P25) was added to the above solution and the $\mathrm{PH}$ was kept to 9.0 for $1 \mathrm{~h}$ by adding $\mathrm{NaOH}$. The slurry was heated to $65^{\circ} \mathrm{C}$ and magnetically stirred for $1 \mathrm{~h}$. After centrifugation and washed with ultrapure water until free of chloride ions, the resultant solid was dried at $60^{\circ}$ $\mathrm{C}$ overnight and calcined at $250^{\circ} \mathrm{C}$ for $2 \mathrm{~h}$ in air. The actual content of Au was 3.84 wt $\%$ determined by inductively coupled plasma-optical emission spectroscopy (ICP-OES).

Synthesis of $\mathrm{C}-\mathrm{Au} / \mathrm{TiO}_{2}$. $\mathrm{C}-\mathrm{Au} / \mathrm{TiO}_{2}$ was synthesized by colloidal deposition method. $2.6 \mathrm{~mL}$ of $0.045 \mathrm{M} \mathrm{HAuCl}_{4} \cdot 4 \mathrm{H}_{2} \mathrm{O}$ solution and $3.33 \mathrm{~mL}$ of $0.5 \mathrm{wt} \% \mathrm{PVA}$ (Mw 10,000; $80 \%$ hydrolyzed) solution were added to $100 \mathrm{~mL}$ ultrapure water After stirring for $30 \mathrm{~min}, 6.6 \mathrm{~mL} \mathrm{NaBH}_{4}\left(0.1 \mathrm{~mol} \mathrm{~L}^{-1}\right)$ solution was rapidly added into the above solution and a dark-brown solution was produced, indicating the formation of gold colloid. $0.5 \mathrm{~g}$ of $\mathrm{TiO}_{2}$ (Degussa P25) was added under vigorous stirring. After stirred for $6 \mathrm{~h}$, the solid was washed with ultrapure water and dried at $60^{\circ} \mathrm{C}$ overnight, followed by heating at $300^{\circ} \mathrm{C}$ for $2 \mathrm{~h}$ in $10 \mathrm{vol} \% \mathrm{O}_{2} / \mathrm{He}$ to remove PVA. The resulting sample was denoted as $\mathrm{C}-\mathrm{Au} / \mathrm{TiO}_{2}$.

Synthesis of $\mathbf{A u} / \mathrm{TiO}_{\mathbf{2}}-\mathbf{H} \mathbf{5 0 0}$. The $\mathrm{Au} / \mathrm{TiO}_{2}-\mathrm{H} 500$ was synthesized by reducing $\mathrm{Au} / \mathrm{TiO}_{2}$ under $10 \mathrm{vol} \% \mathrm{H}_{2} / \mathrm{He}$ at $500^{\circ} \mathrm{C}$ for $1 \mathrm{~h}$ following a previously reported procedure $^{28}$

Synthesis of $\mathbf{A u} / \mathrm{TiO}_{\mathbf{2}}-\mathbf{H 5 0 0 - 8 0 0}$. The $\mathrm{Au} / \mathrm{TiO}_{2}-\mathrm{H} 500-800$ was synthesized by directly calcining $\mathrm{Au} / \mathrm{TiO}_{2}-\mathrm{H} 500$ at $800{ }^{\circ} \mathrm{C}$ in air for $3 \mathrm{~h}$ at a heating rate of $2{ }^{\circ} \mathrm{C}$ $\min ^{-1}$.

Synthesis of $\mathbf{A u} / \mathrm{TiO}_{\mathbf{2}}-\mathbf{H 5 0 0 - 0 4 0 0}$. The $\mathrm{Au} / \mathrm{TiO}_{2}-\mathrm{H} 500-\mathrm{O} 400$ was synthesized by reoxidizing $\mathrm{Au} / \mathrm{TiO}_{2}-\mathrm{H} 500$ under $10 \mathrm{vol} \% \mathrm{O}_{2} / \mathrm{He}$ flow at $400{ }^{\circ} \mathrm{C}$ for $1 \mathrm{~h}$ following a previously reported procedure ${ }^{28}$.

Synthesis of $\mathbf{A u} / \mathrm{TiO}_{2}-\mathbf{H} 500-\mathbf{0 4 0 0}-\mathbf{8 0 0}$. The $\mathrm{Au} / \mathrm{TiO}_{2}-\mathrm{H} 500-\mathrm{O} 400-800$ was synthesized by directly calcining $\mathrm{Au} / \mathrm{TiO}_{2}-\mathrm{H} 500-\mathrm{O} 400$ at $800{ }^{\circ} \mathrm{C}$ in air for $3 \mathrm{~h}$ at a heating rate of $2^{\circ} \mathrm{C} \mathrm{min}^{-1}$.

Synthesis of $\mathbf{A u} / \mathbf{T i O} \mathbf{Z}_{\mathbf{2}} @ \mathbf{M}-\mathbf{N}-\mathbf{8 0 0}$. Typically, $0.15 \mathrm{~g}$ as-synthesized $\mathrm{Au} / \mathrm{TiO}_{2}$ was added to the melamine-containing $\left(1.67 \mathrm{mg} \mathrm{mL}^{-1}\right)$ solution $(30 \mathrm{~mL})$ and the slurry was stirred at $65^{\circ} \mathrm{C}$ for $24 \mathrm{~h}$. After centrifugation and washed with ultrapure water, the product was dried at $60^{\circ} \mathrm{C}$ overnight. The obtained sample was denoted as $\mathrm{Au} /$ $\mathrm{TiO}_{2} @ \mathrm{M}$ and then annealed at $600{ }^{\circ} \mathrm{C}$ in $\mathrm{N}_{2}$ flow for $3 \mathrm{~h}$ at a heating rate of $5{ }^{\circ} \mathrm{C}$ $\mathrm{min}^{-1}$. The resulting sample was denoted as $\mathrm{Au} / \mathrm{TiO}_{2} @ \mathrm{M}-\mathrm{N}$. Then the $\mathrm{Au} /$ $\mathrm{TiO}_{2} @ \mathrm{M}-\mathrm{N}-800$ was synthesized by calcining $\mathrm{Au} / \mathrm{TiO}_{2} @ \mathrm{M}-\mathrm{N}$ at $800^{\circ} \mathrm{C}$ in air for 3 $\mathrm{h}$ at a heating rate of $2^{\circ} \mathrm{C} \mathrm{min}^{-1}$.

Synthesis of Au/TiO $\mathbf{T}_{\mathbf{2}} @ \mathbf{M}-\mathbf{T}$. The $\mathrm{Au} / \mathrm{TiO}_{2} @ \mathrm{M}-\mathrm{T}$ series were synthesized by directly calcining $\mathrm{Au} / \mathrm{TiO}_{2} @ \mathrm{M}$ in air at different temperature for $3 \mathrm{~h}$ at a heating rate of $2^{\circ} \mathrm{C} \mathrm{min}-1$, where $\mathrm{T}(600,800)$ represents the calcining temperature $\left({ }^{\circ} \mathrm{C}\right)$.

Synthesis of Au/TiO ${ }_{\mathbf{2}} @ \mathbf{M}-\mathbf{N 8 0 0}$. The Au/TiO $\mathrm{T}_{2} @ \mathrm{M}-\mathrm{N} 800$ was synthesized by calcining $\mathrm{Au} / \mathrm{TiO}_{2} @ \mathrm{M}$ in $\mathrm{N}_{2}$ at $800^{\circ} \mathrm{C}$ for $3 \mathrm{~h}$ at a heating rate of $5^{\circ} \mathrm{C} \mathrm{min}-1$.

Synthesis of Au/TiO $\mathbf{2}_{\mathbf{2}} @ \mathbf{M}-\mathbf{N}-\mathbf{T}$. The Au/TiO calcining Au/ $\mathrm{TiO}_{2} @ \mathrm{M}-\mathrm{N}$ in air at different temperature for $3 \mathrm{~h}$ at a heating rate of $2{ }^{\circ} \mathrm{C} \min ^{-1}$, where $\mathrm{T}(500,600)$ represents the calcining temperature $\left({ }^{\circ} \mathrm{C}\right)$.

Synthesis of Au/TiO ${ }_{\mathbf{2}} @ \mathbf{M}-\mathbf{N}-\mathbf{8 0 0}-\mathbf{T}$. The Au/TiO $@ @ M-N-800-\mathrm{T}$ series were synthesized by calcining $\mathrm{Au} / \mathrm{TiO}_{2} @ \mathrm{M}-\mathrm{N}-800$ in air at different temperature for $3 \mathrm{~h}$ at a heating rate of $2^{\circ} \mathrm{C} \mathrm{min}^{-1}$, where $\mathrm{T}(400,500,600)$ represents the calcining temperature $\left({ }^{\circ} \mathrm{C}\right)$.

Synthesis of $\mathbf{A u} / \mathrm{TiO}_{\mathbf{2}}-\mathbf{8 0 0}$. The $\mathrm{Au} / \mathrm{TiO}_{2}-800$ was synthesized by directly calcining $\mathrm{Au} / \mathrm{TiO}_{2}$ at $800^{\circ} \mathrm{C}$ in air for $3 \mathrm{~h}$ at a heating rate of $2{ }^{\circ} \mathrm{C} \mathrm{min}-1$.
Synthesis of $\mathbf{A u} / \mathrm{TiO}_{2}-\mathbf{N}-\mathbf{8 0 0}$. The $\mathrm{Au} / \mathrm{TiO}_{2}-\mathrm{N}-800$ was synthesized by calcining $\mathrm{Au} / \mathrm{TiO}_{2}$ in $\mathrm{N}_{2}$ at $600^{\circ} \mathrm{C}$ for $3 \mathrm{~h}$ at a heating rate of $5^{\circ} \mathrm{C} \mathrm{min}^{-1}$, followed by calcining at $800^{\circ} \mathrm{C}$ in air for $3 \mathrm{~h}$ at a heating rate of $2^{\circ} \mathrm{C} \mathrm{min}^{-1}$.

Synthesis of $\mathbf{A u} /$ anatase@M-N-800. The synthesis procedure of Au/anatase@M-N-800 is similar to that of $\mathrm{Au} / \mathrm{TiO}_{2} @ \mathrm{M}-\mathrm{N}-800$ except anatase was sued instead of $\mathrm{TiO}_{2}$.

Synthesis of Au/rutile@M-N-800. The synthesis procedure of Au/rutile@M-N800 is similar to that of Au/rutile@M-N-800 except rutile was sued instead of $\mathrm{TiO}_{2}$.

Synthesis of C-Au/TiO $@ @ M-N-800$. The synthesis procedure of C-Au/TiO ${ }_{2} @ M-$ $\mathrm{N}-800$ is similar to that of $\mathrm{Au} / \mathrm{TiO}_{2} @ \mathrm{M}-\mathrm{N}-800$ except C- $\mathrm{Au} / \mathrm{TiO}_{2}$ was sued instead of $\mathrm{Au} / \mathrm{TiO}_{2}$.

Synthesis of RR2Ti@M-N-800. The commercial gold catalyst RR2Ti was supplied by Haruta Gold Inc. The synthesis procedure of RR2Ti@M-N-800 is similar to that of $\mathrm{Au} / \mathrm{TiO}_{2} @ \mathrm{M}-\mathrm{N}-800$ except RR2Ti was sued instead of $\mathrm{Au} / \mathrm{TiO}_{2}$.

Characterization. XRD patterns were collected on a PANalytical X'Pert Pro diffractometer with $\mathrm{Cu} \mathrm{Ka}$ radiation $(\lambda=0.15432 \mathrm{~nm})$. The gold content was determined by inductively coupled plasma-optical emission spectroscopy analysis (Perklin-Elmer 2100 DV). TEM and HRTEM were performed on JEM-2100 electron microscopy (JEOL) with an acceleration voltage of $200 \mathrm{kV}$. EELS analysis was carried out on an FEI Tecnai G2 F20 microscope equipped with Gatan Imaging Filter (GIF) system operated at $200 \mathrm{kV}$. The chemical compositions of the covering layer of $\mathrm{Au}$ NPs were characterized by directly putting electron beam at the Au NPs in a STEM mode. In situ DRIFTS spectra were recorded on Bruker Equinox 70 spectrometer equipped with MCT detector and operated at a resolution of $4 \mathrm{~cm}^{-1}$. Before CO adsorption, the samples were pretreated with $\mathrm{He}$ at $120^{\circ} \mathrm{C}$ for $1 \mathrm{~h}$ and then cooled to room temperature. The background spectrum was collected in following $\mathrm{He}$ and then the gas $(3 \mathrm{vol} \% \mathrm{CO} / \mathrm{He})$ was introduced into the reaction cell at a total flow rate of $33.3 \mathrm{~mL} \mathrm{~min}{ }^{-1}$. The spectra were recorded until the peak intensity was steady. The blank test was carried out following the exactly same procedure just without catalyst. X-ray photoelectron spectroscopy measurements (XPS) were collected on Thermo Fisher Scientific ESCALAB 250 spectrometer with monochromatic Al Ka (1486.6 $\mathrm{eV}) \mathrm{X}$-ray source. The binding energy (BE) value of $\mathrm{C} 1 s$ at $284.6 \mathrm{eV}$ was used as the reference. X-ray adsorption fine structure (XAFS) measurements at $\mathrm{Au} \mathrm{L}_{\mathrm{III}}$-edge in fluorescence mode were performed at Beamline 1W1B in Beijing Synchrotron Radiation Facility (BSRF). The electron storage ring was operated at $\sim 200 \mathrm{~mA}$ and $\sim 2.2 \mathrm{GeV}$ with a top-up injection mode. A double-crystal Si (111) monochromator was used to scan X-ray energy for X-ray adsorption near edge (XANES) spectra and extended X-ray fine structure (EXAFS) spectra, respectively. The Au foil was used as reference for X-ray energy calibration. Data processing and analysis were performed by Demeter software package. The crystallographic structure of $\mathrm{Au} \mathrm{Au}_{2} \mathrm{O}_{3}, \mathrm{AuTi}$ were used as models for EXAFS fitting.

Catalytic activity measurement. CO oxidation was carried out in a fixed-bed reactor under atmospheric pressure. The gaseous mixture of $1 \mathrm{vol} \% \mathrm{CO}+1 \mathrm{vol} \%$ $\mathrm{O}_{2}$ and $\mathrm{He}$ balance $\left(33.3 \mathrm{~mL} \mathrm{~min}^{-1}\right)$ was passed through the catalysts. The unreacted reactants and products were analyzed online by gas chromatograph equipped with a TCD detector. WGS reaction was performed in the same reactor as was used for $\mathrm{CO}$ reaction and a mixture of $2 \mathrm{vol} \% \mathrm{CO}+10 \mathrm{vol} \% \mathrm{H}_{2} \mathrm{O}$ and $\mathrm{He}$ balance was used with a space velocity of $18 \mathrm{~L} \mathrm{~h}^{-1} \mathrm{~g}_{\text {cat }}{ }^{-1}$. The simulated CO emission control test was carried out in the same reactor and the feed gas was 1.6 vol $\% \mathrm{CO}+1 \mathrm{vol} \% \mathrm{O}_{2}+0.01$ vol $\%$ propene $+0.0087 \mathrm{vol} \%$ toluene +10 vol $\%$ water and He balance with a space velocity of $220 \mathrm{~L} \mathrm{~h}^{-1} \mathrm{gcat}^{-1}$. Specific reaction rates and TOF were evaluated by changing the weight of catalysts from $100 \mathrm{mg}$ to $2 \mathrm{mg}$ to guarantee that $\mathrm{CO}$ conversion was below $15 \%$. For each run, the CO conversion was averaged at the steady state and the TOF was calculated according to equation: $\mathrm{TOF}=\mathrm{r}_{\mathrm{CO}}{ }^{*} \mathrm{M}_{\mathrm{Au}} / \mathrm{D}$, where $\mathrm{r}_{\mathrm{CO}}$ is the specific reaction rates.

\section{Data availability}

All data are available within the article and its Supplementary Information file are available from the authors upon reasonable request.

Received: 3 August 2019; Accepted: 19 November 2019; Published online: 19 December 2019

\section{References}

1. Bell, A. T. The impact of nanoscience on heterogeneous catalysis. Science $\mathbf{2 9 9}$ 1688-1691 (2003)

2. Xia, Y. N. Nanoparticles for catalysis. Acc. Chem. Res. 46, 1671-1672 (2013). 
3. Zheng, N. \& Stucky, G. D. A general synthetic strategy for oxide-supported metal nanoparticle catalysts. J. Am. Chem. Soc. 128, 14278-14280 (2006).

4. Schauermann, S., Nilius, N., Shaikhutdinov, S. \& Freund, H.-J. Nanoparticles for heterogeneous catalysis: new mechanistic insights. Acc. Chem. Res. 46, 1673-1681 (2013).

5. Zhang, S. et al. High catalytic activity and chemoselectivity of sub-nanometric Pd clusters on porous nanorods of $\mathrm{CeO}_{2}$ for hydrogenation of nitroarenes. $J$. Am. Chem. Soc. 138, 2629-2637 (2016).

6. Noh, H. et al. An exceptionally stable metal-organic-framework supported molybdenum(VI) oxide catalyst for cyclohexene epoxidation. J. Am. Chem. Soc. 138, 14720-14726 (2016).

7. $\mathrm{Gu}, \mathrm{D}$. et al. Gold on different manganese oxides: ultra-low-temperature $\mathrm{CO}$ oxidation over colloidal gold supported on bulk- $\mathrm{MnO}_{2}$ nanomaterials. J. Am. Chem. Soc. 138, 9572-9580 (2016).

8. Zhang, J. et al. A Pd@zeolite catalyst for nitroarene hydrogenation with high product selectivity by sterically controlled adsorption in the zeolite micropores. Angew. Chem., Int. Ed. 56, 9747-9751 (2017).

9. Behrens, M. et al. The active site of methanol synthesis over $\mathrm{Cu} / \mathrm{ZnO} / \mathrm{Al}_{2} \mathrm{O}_{3}$ industrial catalysts. Science 336, 893-897 (2012).

10. Graciani, J. et al. Highly active copper-ceria and copper-ceria-titania catalysts for methanol synthesis from $\mathrm{CO}_{2}$. Science 345, 546-550 (2014).

11. Haruta, M., Kobayashi, T., Sano, H. \& Yamada, N. Novel gold catalysts for the oxidation of carbon monoxide at a temperature far below $0{ }^{\circ} \mathrm{C}$. Chem. Lett. 16, 405-408 (1987).

12. Haruta, M. Gold rush. Nature 437, 1098-1099 (2005).

13. Corma, A. \& Serna, P. Chemoselective hydrogenation of nitro compounds with supported gold catalysts. Science 313, 332-334 (2006).

14. Chen, M. S. \& Goodman, D. W. The structure of catalytically active gold on titania. Science 306, 252-255 (2004).

15. Hutchings, G. A golden future. Nat. Chem. 1, 584 (2009).

16. K. Hashmi, A. S. Homogeneous catalysis by gold. Gold. Bull. 37, 51-65 (2004).

17. Haruta, M. Size- and support-dependency in the catalysis of gold. Catal. Today 36, 153-166 (1997)

18. Wolf, A. \& Schüth, F. A systematic study of the synthesis conditions for the preparation of highly active gold catalysts. Appl. Catal., A. 226, 1-13 (2002).

19. Zanella, R. \& Louis, C. Influence of the conditions of thermal treatments and of storage on the size of the gold particles in $\mathrm{Au} / \mathrm{TiO}_{2}$ samples. Catal. Today 107-108, 768-777 (2005).

20. Laursen, A. B. et al. Substrate size-selective catalysis with zeolite-encapsulated gold nanoparticles. Angew. Chem., Int. Ed. 49, 3504-3507 (2010).

21. Wang, S. et al. Aggregation-free gold nanoparticles in ordered mesoporous carbons: toward highly active and stable heterogeneous catalysts. J. Am. Chem. Soc. 135, 11849-11860 (2013).

22. Arnal, P. M., Comotti, M. \& Schuth, F. High-temperature-stable catalysts by hollow sphere encapsulation. Angew. Chem., Int. Ed. 45, 8224-8227 (2006).

23. Zhan, W. et al. A sacrificial coating strategy toward enhancement of metalsupport interaction for ultrastable Au nanocatalysts. J. Am. Chem. Soc. 138 16130-16139 (2016).

24. Zhan, W. et al. Surfactant-assisted stabilization of Au colloids on solids for heterogeneous catalysis. Angew. Chem., Int. Ed. 56, 4494-4498 (2017).

25. Zhang, J. et al. Sinter-resistant metal nanoparticle catalysts achieved by immobilization within zeolite crystals via seed-directed growth. Nat. Catal. 1, 540-546 (2018).

26. Wang, C. et al. Precisely applying $\mathrm{TiO}_{2}$ overcoat on supported Au catalysts using atomic layer deposition for understanding the reaction mechanism and improved activity in CO oxidation. J. Phys. Chem. C 120, 478-486 (2015).

27. Tang, H. et al. Ultrastable hydroxyapatite/titanium-dioxide-supported gold nanocatalyst with strong metal-support interaction for carbon monoxide oxidation. Angew. Chem., Int. Ed. 55, 10606-10611 (2016).

28. Tang, H. et al. Classical strong metal-support interactions between gold nanoparticles and titanium dioxide. Sci. Adv. 3, el700231 (2017).

29. Wang, L. et al. Strong metal-support interactions achieved by hydroxide-tooxide support transformation for preparation of sinter-resistant gold nanoparticle catalysts. ACS Catal. 7, 7461-7465 (2017).

30. Zhang, J. et al. Wet-chemistry strong metal-support interactions in titaniasupported Au catalysts. J. Am. Chem. Soc. 141, 2975-2983 (2019).

31. Dick, K., Dhanasekaran, T., Zhang, Z. \& Meisel, D. Size-dependent melting of silica-encapsulated gold nanoparticles. J. Am. Chem. Soc. 124, 2312-2317 (2002).

32. Li, W. Z. et al. Stable platinum nanoparticles on specific $\mathrm{MgAl}_{2} \mathrm{O}_{4}$ spinel facets at high temperatures in oxidizing atmospheres. Nat. Commun. 4, 2481 (2013).

33. Yang, X. et al. Taming the stability of Pd active phases through a compartmentalizing strategy toward nanostructured catalyst supports. Nat. Commun. 10, 1611 (2019).

34. Lu, J. et al. Coking- and sintering-resistant palladium catalysts achieved through atomic layer deposition. Science 335, 1205-1208 (2012).

35. Aydin, C., Lu, J., Browning, N. D. \& Gates, B. C. A "smart" catalyst: sinterresistant supported iridium clusters visualized with electron microscopy. Angew. Chem., Int. Ed. 51, 5929-5934 (2012).
36. Cao, A., Lu, R. \& Veser, G. Stabilizing metal nanoparticles for heterogeneous catalysis. Phys. Chem. Chem. Phys. 12, 13499-13510 (2010).

37. Tauster, S. J., Fung, S. C. \& Garten, R. L. Strong metal-support interactions. Group 8 noble metals supported on $\mathrm{TiO}_{2}$. J. Am. Chem. Soc. 100, 170-175 (1978)

38. Tauster, S. J., Fung, S. C., Baker, R. T. K. \& Horsley, J. A. Strong interactions in supported-metal catalysts. Science 211, 1121-1125 (1981).

39. Tauster, S. J. Strong metal-support interactions. Acc. Chem. Res. 20, 389-394 (1987).

40. Belton, D. N., Sun, Y.-M. \& White, J. M. Encapsulation and electronic effects in a thin-film model of a Rhodium-Titania strong metal-support interaction catalysts. J. Am. Chem. Soc. 106, 3059-3060 (1984).

41. Bracy, J. D. \& Burch, R. Enhanced activity of $\mathrm{Pd} / \mathrm{TiO}_{2}$ catalysts for the $\mathrm{CO} / \mathrm{H}_{2}$ reaction in the absence of strong metal-support interactions (SMSI). J. Catal. 86, 384-391 (1984).

42. Belzunegui, J. P., Sanz, J. \& Rojo, J. M. Contribution of physical blocking and electronic effect to establishment of strong metal-support interaction in $\mathrm{Rh} /$ $\mathrm{TiO}_{2}$ catalysts. J. Am. Chem. Soc. 114, 6749-6754 (1992).

43. Fan, L. \& Fujimoto, K. Promotive SMSI effect for hydrogenation of carbon dioxide to methanol on a $\mathrm{Pd} / \mathrm{CeO}_{2}$ catalyst. J. Catal. 150, 217-220 (1994).

44. Weerachawanasak, P. et al. Effect of strong metal-support interaction on the catalytic performance of $\mathrm{Pd} / \mathrm{TiO}_{2}$ in the liquid-phase semihydrogenation of phenylacetylene. J. Catal. 262, 199-205 (2009)

45. $\mathrm{Li}, \mathrm{S}$. et al. Tuning the selectivity of catalytic carbon dioxide hydrogenation over Iridium/Cerium oxide catalysts with a strong metal-support interaction. Angew. Chem., Int. Ed. 56, 10761-10765 (2017).

46. Matsubu, J. C. et al. Adsorbate-mediated strong metal-support interactions in oxide-supported Rh catalysts. Nat. Chem. 9, 120-127 (2017).

47. Dong, J. H., Fu, Q., Jiang, Z., Mei, B. B. \& Bao, X. H. Carbide supported Au catalysts for water gas shift reactions: a new territory for the strong metalsupport interaction efect. J. Am. Chem. Soc. 140, 13808-13816 (2018).

48. Hernandez Mejia, C., van Deelen, T. W. \& de Jong, K. P. Activity enhancement of cobalt catalysts by tuning metal-support interactions. Nat. Commun. 9, 4459 (2018).

49. Gao, Y., Liang, Y. \& Chambers, S. A. Thermal stability and the role of oxygen vacancy defects in strong metal support interaction-Pt on $\mathrm{Nb}$-doped $\mathrm{TiO}_{2}(100)$. Surf. Sci. 365, 638-648 (1996).

50. Meyer, R., Lemire, C., Shaikhutdinov, S. K. \& H.-J., F. Surface chemistry of catalysis by gold. Gold. Bull. 37, 72-124 (2004).

51. Fu, Q., Wagner, T., Olliges, S. \& Carstanjen, H.-D. Metal-oxide interfacial reactions: encapsulation of $\mathrm{Pd}$ on $\mathrm{TiO}_{2}$ (110). J. Phys. Chem. B. 109, 944-951 (2005).

52. Goodman, D. W. "Catalytically active Au on titania": yet another example of a strong metal support interaction (SMSI)? Catal. Lett. 99, 1-4 (2005).

53. Liu, X. et al. Strong metal-support interactions between gold nanoparticles and $\mathrm{ZnO}$ nanorods in CO oxidation. J. Am. Chem. Soc. 134, 10251-10258 (2012).

54. Tang, H. et al. Strong metal-support interactions between gold nanoparticles and nonoxides. J. Am. Chem. Soc. 138, 56-59 (2016).

55. Zhang, S. et al. Dynamical observation and detailed description of catalysts under strong metal-support interaction. Nano Lett. 16, 4528-4534 (2016).

56. Pesty, F., Steinriick, H.-P. \& Madey, T. E. Thermal stability of Pt films on TiO2 (110): evidence for encapsulation. Surf. Sci. 339, 82-95 (1995).

57. Green, I. X., Tang, W., Neurock, M. \& Yates, J. T. Jr Spectroscopic observation of dual catalytic sites during oxidation of $\mathrm{CO}$ on a $\mathrm{Au} / \mathrm{TiO}_{2}$ catalyst. Science 333, 736-739 (2011).

58. Mihaylov, M., Knözinger, H., Hadjiivanov, K. \& Gates, B. C. Characterization of the oxidation states of supported gold species by IR spectroscopy of adsorbed CO. Chem. Ing. Tech. 79, 795-806 (2007).

59. Abdel-Mageed, A. M., Kučerová, G., Bansmann, J. \& Behm, R. J. Active Au species during the low-temperature water gas shift reaction on $\mathrm{Au} / \mathrm{CeO}_{2}$ : a timeresolved operando XAS and DRIFTS study. ACS Catal. 7, 6471-6484 (2017).

60. Svanidze, E. et al. High hardness in the biocompatible intermetallic compound $\beta-\mathrm{Ti}_{3} \mathrm{Au}$. Sci. Adv. 2, e1600319 (2016).

61. Beard, B. C. \& Ross, P. N. Pt-Ti alloy formation from high-temperature reduction of a Titania-impregnated Pt catalyst: implications for strong metalsupport interaction. J. Phys. Chem. 90, 6811-6817 (1986).

62. Sakellson, S., McMillan, M. \& Haller, G. L. EXAFS evidence for direct metalmetal bonding in reduced $\mathrm{Rh} / \mathrm{TiO}_{2}$ catalysts. J. Phys. Chem. 90, 1733-1736 (1986).

63. Freund, H. J., Meijer, G., Scheffler, M., Schlogl, R. \& Wolf, M. CO oxidation as a prototypical reaction for heterogeneous processes. Angew. Chem., Int. Ed. 50, 10064-10094 (2011)

\section{Acknowledgements}

This work was financially supported by the National Natural Science Foundation of China (21476232, 21607029), the International Partnership Program of Chinese Academy of Sciences (No.121421KYSB20170020) and the State Key Laboratory of Catalysis in Dalian Institute of Chemical Physics (N-16-07). 


\section{Author contributions}

S.F.L. performed all the experimental work, including material synthesis, catalyst characterization and test. W.X. and L.R.Z. carried out the XAFS experiment. Y.M.N. and B.S. Z. performed EELS experiment. S.F.L. and W.L. performed the electron-microscopy characterization. L.L. carried out CO-DRIFT experiment. All the authors discussed the result and commented on the manuscript. S.F.L. and J.H.W. wrote and revised the paper.

\section{Competing interests}

The authors declare no competing interests.

\section{Additional information}

Supplementary information is available for this paper at https://doi.org/10.1038/s41467019-13755-5.

Correspondence and requests for materials should be addressed to J.W.

Peer review information Nature Communications thanks James H. Carter and Liang Wang for their contribution to the peer review of this work. Peer reviewer reports are available.
Reprints and permission information is available at http://www.nature.com/reprints

Publisher's note Springer Nature remains neutral with regard to jurisdictional claims in published maps and institutional affiliations.

(c) Open Access This article is licensed under a Creative Commons Attribution 4.0 International License, which permits use, sharing, adaptation, distribution and reproduction in any medium or format, as long as you give appropriate credit to the original author(s) and the source, provide a link to the Creative Commons license, and indicate if changes were made. The images or other third party material in this article are included in the article's Creative Commons license, unless indicated otherwise in a credit line to the material. If material is not included in the article's Creative Commons license and your intended use is not permitted by statutory regulation or exceeds the permitted use, you will need to obtain permission directly from the copyright holder. To view a copy of this license, visit http://creativecommons.org/ licenses/by/4.0/.

(c) The Author(s) 2019 